\title{
ULTRASONIC EXTRACTION FOR PREPARATION OF PLANT EXTRACTS WITH BIOINSECTICIDAL EFFECTS ON PEST FROM SEED DEPOSITS
}

\author{
GABRIEL MIHAITA DARABAN ${ }^{a}$, CARMEN ZAHARIA ${ }^{a}$, \\ LACRAMIOARA RUSU ${ }^{b}$, ADRIAN CATALIN PUITEL ${ }^{a}$, \\ MARINELA BADEANU ${ }^{c}$, DANIELA SUTEU ${ }^{\mathrm{a} *}$
}

\begin{abstract}
This paper describes the preparation of plant extracts using solid-liquid ultrasonic extraction (sonoextraction), the characterization of prepared extracts and their bioinsecticidal activity. The studied raw vegetal material:Primula veris, Achillea millefolium, Origanum vulgare and Artemisia absinthium, was collected from the spontaneous flora of Romania, Moldova region. To assess the efficiency of solid-liquid sonoextraction process, the influence of some operating parameters such as solid/liquid ratio, extraction time, extraction temperature, and extraction efficiency was studied. The qualitative study has in view the interpretation of UV-VIS spectra recorded for the extracts, and the quantitative study consists in the estimation of total polyphenols and flavonoids content of prepared vegetal extracts. The resulted data indicate that the content of polyphenols and flavonoids is dependent of the extraction temperature, extraction time and solid/liquid extraction ratio. The bioinsecticidal activity of Origanum vulgare and Artemisia absinthium extracts was evaluated on the Acanthoscelides obtectus (commonly named as ladybug bean) using two application techniques (i.e. direct and indirect application using a cellulose disk as a porous material impregnated with extract that allows controlled evaporation), being registered a mortality rate of adults in the range of $35-55 \%$. Therefore, the studied extracts proved to be effective in controlling ladybug bean from seed stores.
\end{abstract}

Keywords: Acanthoscelides obtectus (ladybug bean), bioinsecticidal activity, chemical characterization, vegetal extract, sono- extraction

a "Gheorghe Asachi" Technical University, lasi, Romania; "Ion lonescu de la Brad" University of Life Science, lasi, Romania; "Cristofor Simionescu" Faculty of Chemical Engineering and Environmental Protection, lasi, Romania.

b "Vasile Alecsandri" University of Bacau, Faculty of Engineering, Bacau, Romania

c "Ion lonescu de la Brazi" University of Agricultural Sciences and Veterinary Medicine of lasi,

Faculty of Horticulture, lasi, Romania

*Corresponding author: danasuteu67@yahoo.com 
GABRIEL MIHAITA DARABAN, CARMEN ZAHARIA, LACRAMIOARA RUSU, ADRIAN CATALIN PUITEL, MARINELA BADEANU, DANIELA SUTEU

\section{INTRODUCTION}

In order to protect the food seeds, a series of plant extracts can be successfully used instead of chemical synthesis pesticides.

Assurance of life quality is today one of the key objectives of any economic, agricultural or social activity. The people's life quality concept refers both to the quality of products and services they use, and to the quality of the environment in which they live their lives. An important category of products that directly influence people's health is food and the raw material for food preparation. In this sense, the practice of a new agriculture, of modern and biodynamic type, in accordance with the principles of environmental sustainability, has become a last resort. Moreover, ecological agriculture (organic farming) involves, among other things, the use in agricultural processes of chemical compounds with the role of pesticides, environmentally friendly to ensure optimal crop development, but protecting both the plant and environmental factors (soil, water, air) from the toxic action of these synthetic compounds. In this context, the finding or development of some alternatives to the chemical products existing on the market or intensively used in the agriculture sector is proposed. The attention was directed to certain plants, known to be real laboratories which can offer numerous metabolites extremely useful in cosmetics, foods, pharmaceutical industries, in development of phyto-pharmaceutics and phytosanitary products [1-5]. In the last times, some compounds with biopesticide action, useful in agriculture for combating pests or keeping certain plant seeds, were identified [6-11]. The advantages of such products instead of chemically synthetized pesticides are mainly due to the lack of toxicity to environmental factors and human bodies, the customization of the dose according to the intended purpose and the possibility of use in the form of raw extract as result of the manifestation of the synergistic effect of the compounds present in extract. Comparatively with the interest zone which targets natural additives, phytosanitary products and phytopharmaceutics for human use, the research in the biopesticide area is only just at the beginning. But they are spurred, encouraged and supported by new regulations in agriculture in order to ensure its sustainability.

Our paper aims is to study the preparation of some vegetal extracts using solid-liquid sono-extraction. In this respect, four plants from the spontaneous flora of the region of Moldova (Romania), respectively, the city of lasi were used: Achillea millefolium (Yarrow), Artemisia absinthium (Wormwood), Origanum vulgare (Oregano) and Primula veris (Primrose), their extracts previously prepared by maceration have indicated corresponding efficiency in combating crop or deposit pests. The study of sono-extraction followed the influence of some physical operating parameters on the 
extraction process, the influence being appreciated by determination of the extraction yield. Preliminary quantitative analysis followed the determination of the total polyphenols and flavonoids content. Also, the bio-insecticidal effect of the extracts on the pests from the seed deposits, respectively the ladybug beans (Acanthoscelides obtectus), was followed.

\section{RESULTS AND DISCUSSION}

The prepared alcoholic extracts had a brown-greenish colour and a characteristic alcoholic odour which, however, retains some of the initial odours of the plants.

\section{Evaluation of the extraction yield}

The calculation of the efficiency of solid-liquid ultrasound-assisted extraction, at different solid/liquid ratios, temperature and time was performed in order to evaluate the extraction performances related to the selected extraction conditions. The results are presented in Table 1. To determine the overall extraction yield, it was necessary to evaporate at the sec a volume of $5 \mathrm{~mL}$ of each vegetal extract, at temperature of $60^{\circ} \mathrm{C}$, using a thermostatic oven, in order to obtain the dry residue.

In the extraction processes, the temperature is one of the important operating parameters, its value influencing the mass transfer of the solute between the solid phase and the solvent, respectively the quantity of the extracted substance under the selected conditions. Also, the extraction yield depends on the quality of the plant material, because it controls the content of useful compounds, the porosity and the permeability to extraction of the solid material. To these are added the preliminary treatments performed on the plant material, such as drying, crushing, sieving and last but not least the type of solvent selected and the ratio in which it is added onto the solid material $(L / S)$. These influences are observed by studying the results experimentally obtained and systematized in Table 1.

The analysis of the data presented in Table 1 highlights the fact that for each studied plant the extraction yield depends on the temperature and the extraction time, but also on the ratio between the two fractions. Analysing the data by plant type, it results that: for Artemisia absinthium the highest percentage of extracted compounds (11.2-11.6\%) was obtained at temperature $35{ }^{\circ} \mathrm{C}$, solid / liquid ratio of $1 / 20$ and an extraction time of 10 and 15 minutes respectively; for Primula veris, the highest percentage (9.37\%) was achieved at $60{ }^{\circ} \mathrm{C}, 15$ minutes extraction and a solid / liquid ratio of 1/10, for Origanum vulgare, the highest percentage of extracted substances $(10-10.88 \%)$ was 
obtained at temperature $60^{\circ} \mathrm{C}$, solid / liquid ratio of $1 / 10-1 / 15$ and an extraction time of 30 minutes, and for Achilleia millefolium, the best results $(9.37 \%)$ were obtained in the following conditions: extraction temperature of $60{ }^{\circ} \mathrm{C}$, solid / liquid ratio of $1 / 10$ and an extraction time of 10 minutes. The conclusion of these data from Table 1 would be that for each plant there are and can be selected distinct conditions that lead to the highest extraction yields, conditions that definitely start from the plant structure, respectively the quantity and type of chemical compounds in their composition. These specific and particular conditions of each plant will be considered for further studies.

Table 1. The extraction yield at different parameters for sono-extraction procedure

\begin{tabular}{|c|c|c|c|c|c|c|}
\hline \multirow{2}{*}{$\begin{array}{l}\text { Process } \\
\text { time } \\
\text { (min) }\end{array}$} & \multirow[b]{2}{*}{$\begin{array}{l}S / L \\
(v / v)\end{array}$} & \multirow{2}{*}{$\begin{array}{c}\text { Extraction } \\
\text { temperature } \\
\left({ }^{0} \mathrm{C}\right)\end{array}$} & \multicolumn{4}{|c|}{ Plant/ extraction yield (\%) } \\
\hline & & & $\begin{array}{c}\text { Origanum } \\
\text { vulgare }\end{array}$ & $\begin{array}{l}\text { Achilleia } \\
\text { millefolium }\end{array}$ & $\begin{array}{l}\text { Artemisia } \\
\text { absinthium }\end{array}$ & $\begin{array}{c}\text { Primula } \\
\text { veris }\end{array}$ \\
\hline \multirow{3}{*}{10} & $1 / 10$ & \multirow{9}{*}{35} & 3.4 & 3.4 & 5.4 & 2.8 \\
\hline & $1 / 15$ & & 6 & 5.4 & 8.7 & 4.8 \\
\hline & $1 / 20$ & & 10 & 8.4 & 11.2 & 7.2 \\
\hline \multirow{3}{*}{15} & $1 / 10$ & & 3.8 & 4.2 & 7.4 & 2.8 \\
\hline & $1 / 15$ & & 5.4 & 6.9 & 9.3 & 3 \\
\hline & $1 / 20$ & & 9.6 & 8.4 & 11.6 & 6.4 \\
\hline \multirow{3}{*}{30} & $1 / 10$ & & 5.5 & 4 & 7 & 2.75 \\
\hline & $1 / 15$ & & 3.75 & 7.5 & 9 & 4.88 \\
\hline & $1 / 20$ & & 10 & 6 & 7.5 & 5 \\
\hline \multirow{3}{*}{10} & $1 / 10$ & \multirow{9}{*}{45} & 5.2 & 6 & 8.8 & 4.2 \\
\hline & $1 / 15$ & & 6 & 6.6 & 8.4 & 3.6 \\
\hline & $1 / 20$ & & 5.6 & 6 & 8.8 & 4.8 \\
\hline \multirow{3}{*}{15} & $1 / 10$ & & 6.8 & 6 & 8.8 & 5 \\
\hline & $1 / 15$ & & 6 & 6 & 9 & 5.7 \\
\hline & $1 / 20$ & & 5.2 & 4.4 & 6.4 & 4.4 \\
\hline \multirow{3}{*}{30} & \multirow{3}{*}{$\begin{array}{l}1 / 10 \\
1 / 15 \\
1 / 20\end{array}$} & & 8 & 6 & 9 & 4.5 \\
\hline & & & 6.75 & 5.62 & 7.5 & 5.25 \\
\hline & & & 7.5 & 7 & 5.5 & 11 \\
\hline \multirow{3}{*}{10} & $1 / 10$ & \multirow{9}{*}{60} & 6.25 & 7.5 & 4.5 & 5.75 \\
\hline & $1 / 15$ & & 3 & 3.75 & 2.75 & 2.75 \\
\hline & $1 / 20$ & & 7 & 4.5 & 10.5 & 8 \\
\hline \multirow{3}{*}{15} & $1 / 10$ & & 7 & 11.25 & 5.25 & 9.37 \\
\hline & $1 / 15$ & & 6.75 & 6.37 & 8.62 & 5.62 \\
\hline & $1 / 20$ & & 7 & 7 & 6.5 & 6 \\
\hline \multirow{3}{*}{30} & $1 / 10$ & & 10.25 & 6 & 3 & 3 \\
\hline & $1 / 15$ & & 10.88 & 6 & 3.38 & 3.75 \\
\hline & $1 / 20$ & & 8.5 & 7.5 & 7.5 & 7 \\
\hline
\end{tabular}




\section{Chemical evaluation of the prepared vegetal extract}

Vegetal extracts are used in their raw form in pest control, not involving a prior separation on components, their action being based on the synergistic effect of the components. However, for the evaluation of the bioinsecticidal action, it is necessary to determine the chemical composition of the extracts obtained in order to identify the large classes of chemical components. In this sense, it was agreed the quantitative determination of the content of total polyphenols and flavonoids, classes of compounds that contain the most active principles responsible for the bioinsecticidal action.

The chemical analysis of all obtained vegetal extracts, based on the Folin-Ciocalteu reaction [14] to determine the total polyphenols content (TPC) and flavonoids content (TF), led to the results presented in Table 2.

Table 2. The content of total polyphenols and flavonoids in the vegetal extracts

\begin{tabular}{|c|c|c|c|c|c|c|c|c|c|c|}
\hline \multirow{3}{*}{$\begin{array}{l}\text { Time } \\
\text { (min) }\end{array}$} & \multirow{3}{*}{$S / L$} & \multirow[b]{3}{*}{$\begin{array}{c}\mathrm{T} \\
\left({ }^{\circ} \mathrm{C}\right)\end{array}$} & \multicolumn{8}{|c|}{ Plant } \\
\hline & & & \multicolumn{2}{|c|}{ Artemisia absinthium } & \multicolumn{2}{|c|}{ Primula veris } & \multicolumn{2}{|c|}{ Origanum vulgare } & \multicolumn{2}{|c|}{ Achilleia millefolium } \\
\hline & & & $\begin{array}{c}\mathrm{C}_{\mathrm{TPC}} \\
(\mu \mathrm{g} / \mathrm{g})\end{array}$ & $\begin{array}{c}\mathrm{C}_{\mathrm{TF}} \\
(\mathrm{mg} / \mathrm{g})\end{array}$ & $\begin{array}{c}\mathrm{C}_{\mathrm{TPC}} \\
(\mu \mathrm{g} / \mathrm{g})\end{array}$ & $\begin{array}{c}\mathrm{C}_{\mathrm{TF}} \\
(\mathrm{mg} / \mathrm{g})\end{array}$ & $\begin{array}{c}\mathrm{C}_{\mathrm{TPC}} \\
(\mu \mathrm{g} / \mathrm{g})\end{array}$ & $\begin{array}{c}\mathrm{C}_{\mathrm{TF}} \\
(\mathrm{mg} / \mathrm{g})\end{array}$ & $\begin{array}{c}\mathrm{C}_{\mathrm{TPC}} \\
(\mu \mathrm{g} / \mathrm{g})\end{array}$ & $\begin{array}{c}\mathrm{C}_{\mathrm{TF}} \\
(\mathrm{mg} / \mathrm{g})\end{array}$ \\
\hline \multirow{3}{*}{10} & $1 / 10$ & \multirow[t]{9}{*}{35} & 0.60 & 13.215 & 0.4 & 12.521 & 1.07 & 16.688 & 0.65 & 17.340 \\
\hline & $1 / 15$ & & 0.69 & 27.522 & 0.66 & 24.509 & 1.01 & 23.908 & 0.53 & 24.250 \\
\hline & $1 / 20$ & & 0.51 & 16.887 & 0.43 & 19.987 & 0.89 & 18.760 & 0.48 & 20.631 \\
\hline \multirow{3}{*}{15} & $1 / 10$ & & 0.71 & 15.303 & 0.47 & 12.657 & 1.14 & 19.096 & 0.61 & 17.353 \\
\hline & $1 / 15$ & & 0.63 & 22.453 & 0.51 & 24.314 & 1.13 & 24.417 & 0.53 & 26.364 \\
\hline & $1 / 20$ & & 0.55 & 18.063 & 0.63 & 24.573 & 1.13 & 22.560 & 0.51 & 22.782 \\
\hline \multirow{3}{*}{30} & $1 / 10$ & & 1.1 & 9.27 & 1.75 & 13.43 & 1.68 & 19.9 & 0.93 & 10.41 \\
\hline & $1 / 15$ & & 0.99 & 6.39 & 1.44 & 16.69 & 1.39 & 11.89 & 1.1 & 14.68 \\
\hline & $1 / 20$ & & 1.1 & 9.27 & 1.75 & 13.43 & 1.68 & 19.9 & 0.93 & 10.41 \\
\hline \multirow{3}{*}{10} & $1 / 10$ & \multirow[t]{9}{*}{45} & 0.93 & 40.244 & 0.78 & 70.276 & 1.56 & 65.432 & 0.93 & 42.255 \\
\hline & $1 / 15$ & & 0.6 & 20.807 & 0.59 & 48.776 & 1.18 & 15.244 & 0.63 & 33.053 \\
\hline & $1 / 20$ & & 0.55 & 18.335 & 0.53 & 23.503 & 1.09 & 24.927 & 0.48 & 25.674 \\
\hline \multirow{3}{*}{15} & $1 / 10$ & & 0.87 & 40.516 & 0.95 & 78.234 & 1.73 & 29.419 & 0.84 & 37.742 \\
\hline & $1 / 15$ & & 0.6 & 25.090 & 0.72 & 34.053 & 1.37 & 31.400 & 0.56 & 46.644 \\
\hline & $1 / 20$ & & 0.47 & 19.392 & 0.49 & 23.056 & 1.03 & 11.912 & 0.48 & 25.123 \\
\hline \multirow{3}{*}{30} & $1 / 10$ & & 1.18 & 10.77 & 1.65 & 16.52 & 1.59 & 12.27 & 0.97 & 12.4 \\
\hline & $1 / 15$ & & 1.19 & 12.52 & 1.52 & 14.18 & 1.47 & 12.85 & 1.04 & 14.81 \\
\hline & $1 / 20$ & & 0.99 & 6.39 & 1.44 & 16.69 & 1.39 & 11.89 & 1.1 & 14.68 \\
\hline \multirow{3}{*}{10} & $1 / 10$ & \multirow[t]{9}{*}{60} & 1 & 5.64 & 2.24 & 22.26 & 2.29 & 20.09 & 1.68 & 17.32 \\
\hline & $1 / 15$ & & 0.87 & 4.7 & 1.99 & 18.25 & 1.97 & 15.2 & 1.25 & 13.82 \\
\hline & $1 / 20$ & & 1.18 & 10.77 & 1.65 & 16.52 & 1.59 & 12.27 & 0.97 & 12.4 \\
\hline \multirow{3}{*}{15} & $1 / 10$ & & 0.96 & 10.84 & 2.22 & 29.9 & 2.22 & 21.64 & 1.67 & 21.84 \\
\hline & $1 / 15$ & & 1.39 & 10.62 & 2.01 & 22.25 & 2.09 & 8.5 & 1.24 & 11.7 \\
\hline & $1 / 20$ & & 1.19 & 12.52 & 1.52 & 14.18 & 1.47 & 12.85 & 1.04 & 14.81 \\
\hline \multirow{3}{*}{30} & $1 / 10$ & & 0.95 & 6.02 & 2.5 & 19.13 & 2.25 & 24.17 & 1.32 & 16.52 \\
\hline & $1 / 15$ & & 0.87 & 4.43 & 2.28 & 12.74 & 2.29 & 18.03 & 1.11 & 11.56 \\
\hline & $1 / 20$ & & 1.22 & 26.04 & 1.1 & 42.56 & 1.06 & 36.25 & 1.24 & 18.622 \\
\hline
\end{tabular}


The amount of extracted compounds depends, in the case of each plant, on the conditions under which the liquid-solid extraction was carried out, the conditions set out above, because they also significantly influence the overall efficiency of the extraction process. Thus, the data presented in Table 2 show the effect of three most significant operational parameters: (A) $S$ / $L$ ratio; $(B)$ extraction time and $(C)$ extraction temperature, on the quantity of extracted compounds. A preliminary analysis of these data in Table 2 shows that the amount of extracted flavonoids is much higher than the polyphenols, which suggests that the bioinsecticidal activity of the extracts may be probable, determined due to the chemical compounds of this class. These results must be analysed for, taking into account the factors that were selected for monitoring the extraction: temperature, phase contact time and phase ratio.

\section{The effect of solid-solvent ratio on total polyphenols (TPCs) and flavonoids (TFs) content}

The influence of the solid / liquid ratio (S / L) (Table 2) was assessed by the values obtained for the content of these compounds present in the plant extract. Comparing the characteristic values of TPC and TF taking into account each plant, it can be concluded that in the case of:

(i) Artemisia absinthium regardless of the extraction temperature, the best values were obtained in the case of $S / L$ ratios of $1 / 10-1 / 15$, i.e. for TPC values were 1.39 and $1.22 \mu \mathrm{g}$ GAE / g, respectively for TFCs, obtained values were 40.515 and $42.25 \mathrm{mg} \mathrm{QE} \mathrm{/} \mathrm{g,} \mathrm{respectively.}$

(ii) Origanum vulgare, analyzing all the values in the Table 2, it seems that for TPCs, the best values are obtained in the case of the phase ratio $S / L$ of $1 / 10(2.29-2.59 \mu \mathrm{g}$ GAE / g) respectively $1 / 15-2.29 \mu \mathrm{g}$ GAE / $\mathrm{g}$, and in the case of TFC, the values obtained depend on the phase ratio but also on the temperature these values; the highest value obtained was 65,432 at a ratio $S$ / $\mathrm{L}$ of $1 / 10$.

(iii) Achilleia millefolium considering the TPC content, the values obtained are close and relatively evenly distributed along the values of the phase ratio and temperature, but the values obtained in the case of the ratio S/L $1 / 10$ of $1.32-1.68 \mu \mathrm{g}$ GAE / g are detached. Regarding the TFCs content, the phase ratio $S / L$ that ensures the highest values is overall $1 / 15$, corresponding to $46.644 \mathrm{mg}$ QE / g.

(iv) Primula veris, the analysis of the TFC content led to the conclusion that overall the $S$ / $L$ ratio of $1 / 10$ ensures the obtaining of the best values for the content of polyphenolic compounds of 2.24-2.5 $\mu \mathrm{g}$ GAE / g. In the case of flavonoids, keep in mind the maximum values of $70,276 \mathrm{mg} \mathrm{QE} / \mathrm{g}$ and $78,234 \mathrm{mg} \mathrm{QE} / \mathrm{g}$ obtained in the case of S / L ratios of 1/10. 


\section{The effect of extraction time on the content of total polyphenols and flavonoids}

The effect of the extraction time can be assessed according to the working temperature (Table 2), different behaviours are identified in this case. Contrary to expectations, the highest values were not recorded at the highest temperature at which the extraction was conducted $\left(60^{\circ} \mathrm{C}\right)$ but at temperatures up to that value, the reason being that the temperature, although it facilitates better phase contact, can also determine destruction of compounds. If we take into account the fact that at extraction temperature of $45^{\circ} \mathrm{C}$ the highest values for calculated sizes were obtained, then it can be concluded that maximum contents for TPC were obtained at an extraction time of $15 \mathrm{~min}$ and $\mathrm{S} / \mathrm{L}$ ratio of 1/10 for Primula veris - $0.95 \mathrm{GAE} / \mathrm{g}$ and Origanum vulgare - $1.73 \mathrm{~g}$ GAE / g) and $10 \mathrm{~min}$ in the case of Artemisia absinthium and Achilleia millefolium -0.93 $\mathrm{g}$ GAE /g. The highest total flavonoid content (TFC) was obtained in the case of an extraction time of $15 \mathrm{~min}$ for Primula veris - $78.23 \mathrm{mg} \mathrm{QE} / \mathrm{g}$, Artemisia absinthium - $40.51 \mathrm{mg} \mathrm{QE} / \mathrm{g}$ and Achilleia millefolium - $46.64 \mathrm{mg} \mathrm{QE} / \mathrm{g}$ and 10 minutes for Origanum vulgare $-65.43 \mathrm{mg} \mathrm{QE} / \mathrm{g}$.

\section{The effect of temperature on the content of total polyphenols and flavonoids in plant extracts}

Temperature is considered an important factor that significantly influences the solid-liquid extraction by intensifying the denaturing of the cell wall of the plant substrate which allows increasing the cell permeability and releasing the organic compounds from the organic matrix to the extraction solvent [16]. Also, in the scientific literature it is shown that an increase of the temperature contributes to the decrease of the surface tension that allows a better wetting of the vegetal material which facilitates a more complete extraction of the tracked products $[16,17]$. However, too high a temperature could distort a number of more temperature sensitive compounds. Table 2 also showed the results on the influence of extraction temperature on the content of total polyphenols and flavonoids in plant extracts obtained by extraction. The values obtained confirm that performing the sono-extraction at a temperature of $45{ }^{\circ} \mathrm{C}$ leads to plant extracts much richer in polyphenols and flavonoids than in the case of the extract made at $35^{\circ} \mathrm{C}$ and $60^{\circ} \mathrm{C}$ respectively.

\section{Physical-chemical characterization of the prepared vegetal extract by UV-VIS spectrometry}

The information resulted through the physical-chemical analysis confirm and complete the information resulting from the quantitative analyses. 
Physical-chemical characterization was made using UV-Vis spectra for only two extracts, of Artemisia absinthium and Origanum vulgare, respectively those that showed significant bio-insecticidal activity on ladybug beans (Acanthoscelides obtectus), according to previous studies performed with vegetal extracts obtained by other liquid-solid extraction techniques (maceration-based extraction techniques) $[18,19]$.

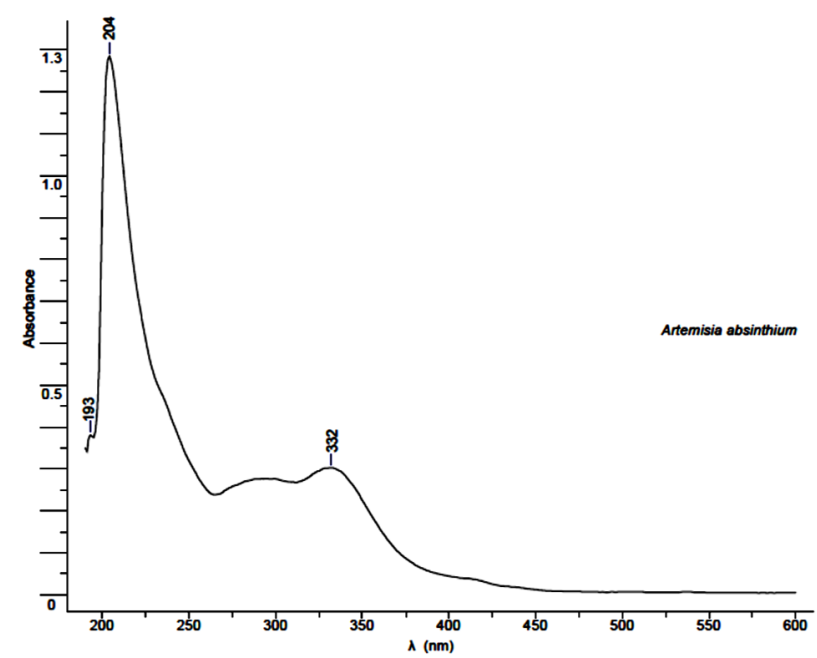

a

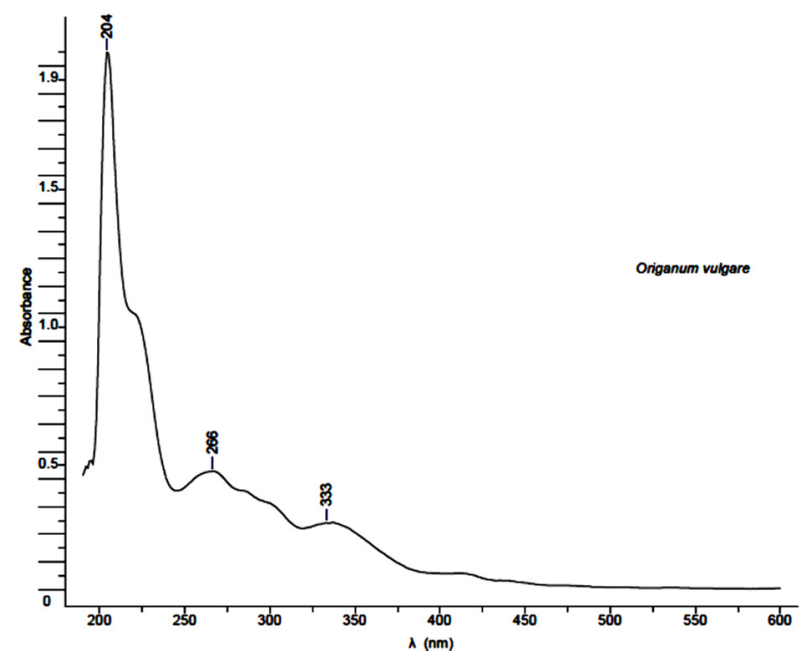

$b$

Figure 1. UV-Vis spectra of vegetal extracts obtained by solid-liquid sonoextraction: (a) Artemisia absinthium; (b) Origanum vulgare 
UV-Vis spectroscopy has been used as a tool to obtain preliminary information about composition, vis-à-vis a number of classes of compounds (e.g., phenols) that may be present in plant extract. For example, in Figure 1, the UV-Vis spectra characteristic of the plant extracts obtained for the Artemisia absinthium and Origanum vulgare are presented.

The UV-Vis spectra study of alcoholic extracts can offer a series of pilot information related to the nature of extracted compounds (Table 3).

Table 3. UV-Vis characteristics of the alcoholic vegetal extracts obtained by solid-liquid sono- extraction (UAE)

\begin{tabular}{|l|l|l|}
\hline \multicolumn{1}{|c|}{ Plant } & \multicolumn{1}{|c|}{$\lambda_{\max }(\mathrm{nm})(\mathrm{UAE})$} & \multicolumn{1}{c|}{ Possible compounds } \\
\hline Artemisia absinthium & $193,204,332$ & $\begin{array}{l}\text { ursolic acid }(210 \mathrm{~nm}) ; \text { ferulic acid }(214 \mathrm{~nm}, \\
325 \mathrm{~nm}) ; \text { rosmarinic acid }(218 \mathrm{~nm}, 330 \mathrm{~nm}) \\
\text { flavanones }(320-330 \mathrm{~nm}) ; \text { quercetin }(256 \mathrm{~nm}, \\
354 \mathrm{~nm}) ; \text { kaempferol }(265 \mathrm{~nm}) ; \text { luteolin }(265 \\
\mathrm{nm}, 330 \mathrm{~nm})\end{array}$ \\
\hline Origanum vulgare & $204,266,333$ & \\
\hline
\end{tabular}

The character of the spectra and characteristic wavelengths are consistent with the data presented in our previous publications about the composition of plant extracts obtained by other methods of extraction liquid - solid.

According with the information presented in table 3 it can be underlined that a general characteristic of vegetal extracts is represented by their high amount of total flavonoids (256-265, $330-333 \mathrm{~nm}$ ) and total polyphenols, which could be correlated with the intensity of the insecticidal effect manifested by these two extracts on ladybug beans (Acanthoscelides obtectus). Taking into account the above presented information, it can conclude that an advanced study on these extracts will allow the punctual identification of the chemical compounds from these two classes to which this effect is due.

\section{Bio-insecticidal activity of the prepared vegetal extracts}

Using the methodology and study procedure previously applied in our studies on the bioinsecticide action of the vegetal extract types $[18,19]$ it was tested the action of two prepared extracts, i.e. Origanum vulgare and Artemisia absinthium species, by ultrasound-assisted extraction under $35^{\circ} \mathrm{C}$ conditions on ladybug beans (Acanthoscelides obtectus). The results obtained are presented in Figure 2. 


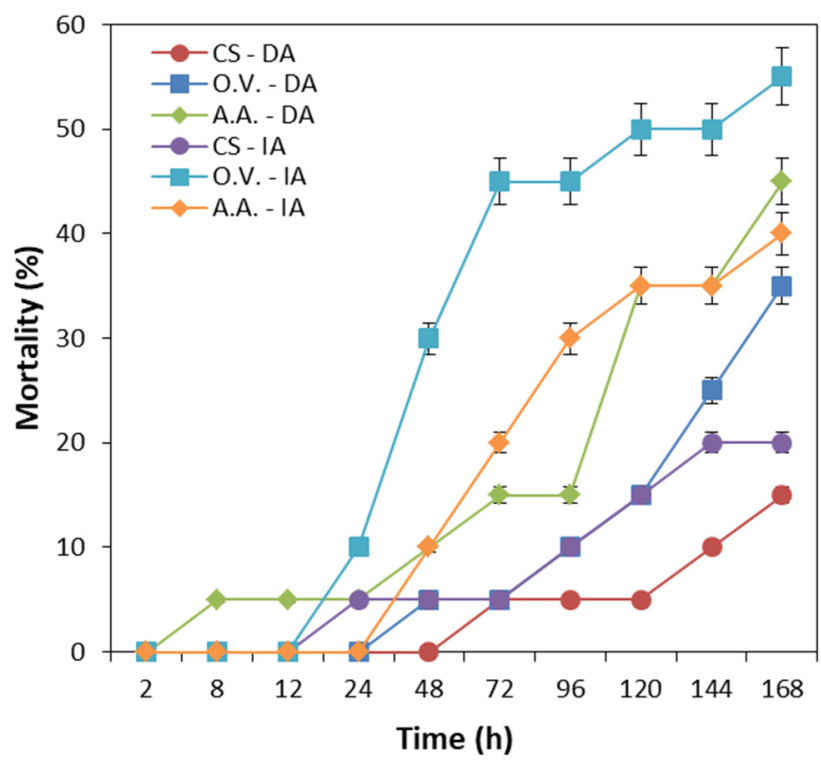

Figure 2. Obtained results about bioinsecticidal activity evaluation in the case of direct and indirect spraying application method (CS - control sample,

O.V. - Origanum vulgare, A.A. - Artemisia absinthium,

DA - direct application, IA - indirect application)

Figure 2 shows that the sprayed extracts has a bio-insecticidal effect on the ladybug beans after a certain contact time (24 or 48 hours, respectively) which is accentuated with the increase of contact time and therefore with the intensification of the application of treatments. At the end of the study time, it was observed that the extract of Artemisia absinthium shows a slightly stronger effect on ladybug beans compared to Origanum vulgare. Also, a better insecticidal action for both extracts is observed in the case of creating a saturated atmosphere in the volatile compounds eliberated from the extract by indirect application than in the case of direct spraying, which from a practical point of view, is much more advantageous and efficient. Correlating these effects of the vegetal extracts with the data presented in Tables 1 and 2, it can be observed that the extract of Artemisia absinthium has superior properties to that of Origanum vulgare, in terms of extraction yield or flavonoid content.

The performances of the ultrasonic extraction in preparation of efficient extracts in combating the bean gargle were compared with our results obtained by other solid-liquid extraction variants, previously studied. The results are shown in Figures 3 and 4. 


\section{ULTRASONIC EXTRACTION FOR PREPARATION OF PLANT EXTRACTS WITH BIOINSECTICIDAL EFFECTS ON PEST FROM SEED DEPOSITS}

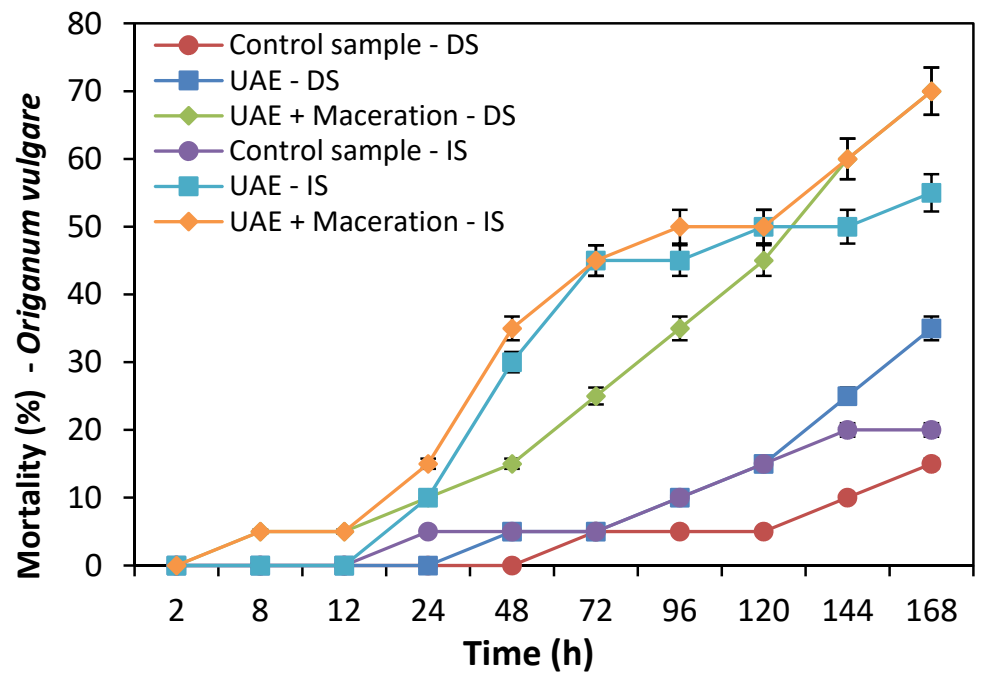

Figure 3. The bio-insecticidal action of Origanum vulgare extract obtained by all our used extraction methods by direct (DS) or indirect spraying (IS) technique (Control sample $D=$ Control sample - Direct Spraying; UAE - DS = UAE - Direct Spraying; UAE + Maceration $-\mathrm{DS}=\mathrm{UAE}+$ Maceration - Direct Spraying; Control sample - IS = Control sample - Indirect Spraying; UAE - IS = UAE - Indirect Spraying; UAE + Maceration - IS = $\mathrm{UAE}+$ Maceration - Indirect Spraying

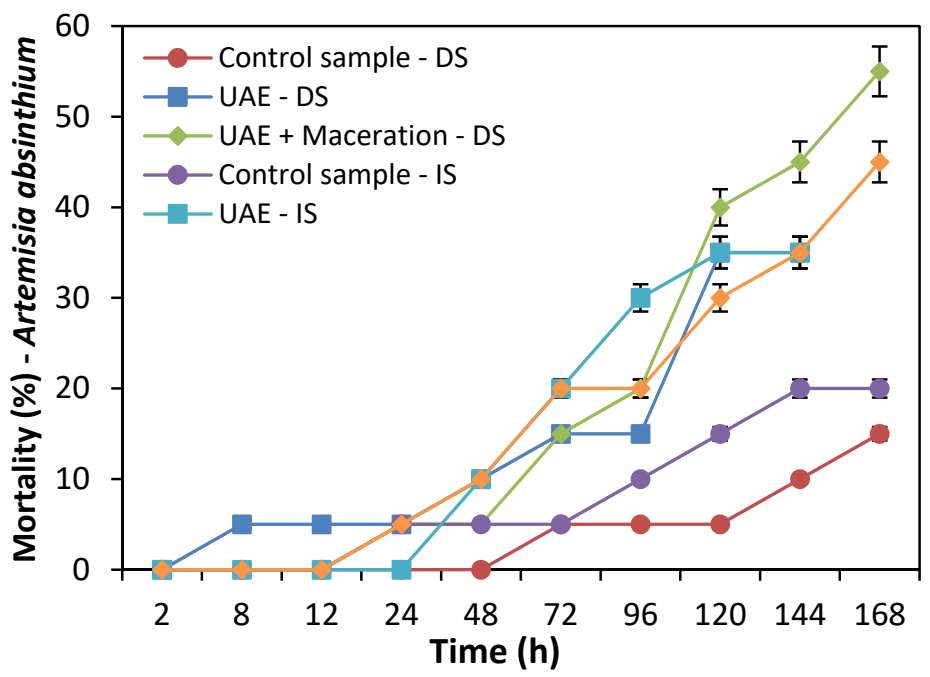

Figure 4. The bio-insecticidal action of Artemisia absinthium extract obtained by all our used extraction methods by direct (DS) or indirect spraying (IS) technique (Control sample $\mathrm{DS}=$ Control sample - Direct Spraying; UAE - DS = UAE - Direct Spraying; UAE + Maceration - DS = UAE + Maceration - Direct Spraying; Control sample - IS = Control sample - Indirect Spraying; UAE - IS = UAE - Indirect Spraying; UAE + Maceration - IS = $\mathrm{UAE}+$ Maceration - Indirect Spraying) 
From figure 3 it is observed that in the case of Origanum vulgare, after the sonoextraction, an extract is obtained whose bio-insecticidal action is superior to all other methods used, in the case of indirect spraying (on a cellulosic disk placed inside with ladybug bean) being surpassed only by subsequent maceration. From figure 4, it is observed that in the case of Artemisia absinthium, after the sonoextraction, an extract is obtained whose bio-insecticidal action is comparable with the other extraction methods used, the indirect spray technique proving much better performances.

\section{CONCLUSIONS}

This work was aimed at preparation of vegetal extracts from a number of characteristic plants of spontaneous flora of Moldova (Romania) (Primula veris, Achilleia millefolium, Origanum vulgare and Artemisia absinthium) by sono-extraction.

For sonoextraction were used flowers, stems and leaves of plants and studied the effects of three physical variables: extraction time, extraction temperature and solid/liquid ratio. The influence of these operating parameters was appreciated by calculating the extraction yields. Vegetal extracts were quantitatively characterized by spectrophotometer-based determination of the total polyphenols and flavonoids content. The results show that the extracts contain appreciable amounts of flavonoids that depend on the time of sonoextraction, extraction temperature and solid/liquid ratio, which can be considered to be responsible for the bioinsecticide action of the extracts. For the evaluation of the bio-insecticidal activity on the ladybug bean (Acanthoscelides obtectus), the Artemisia absinthium and Origanum vulgare extracts were used in experiments. These extracts were selected taking into account the significant in-time increasing bio-insecticidal activity on ladybug beans according to previous studies performed (maceration).

The mortality rate of adults was of $35-55 \%$, thus is reconfirmed their effectiveness in controlling ladybug bean (Acanthoscelides obtectus) from seed stores.

\section{EXPERIMENTAL SECTION}

\section{Plant material}

The plant material used was represented by Yarrow (Achillea millefolium Regn: Plantae; Phylum: Magnoliophyta; Class: Magnoliopsida; Order: Asterales; Family: Asteraceae; Gender: Achillea; Species: millefolium; Binomial name: 
Achillea millefolium, L. 1753), Wormwood (Artemisia absinthium - Regn: Plantae; Phylum: Tracheophytes; Class: Angiosperms; Order: Asterales; Family: Asteraceae; Gender: Artemisia; Species: A. absinthium; Binomial name; Artemisia absinthium L. [1]), Oregano (Origanum vulgare - Regn: Plantae; Division: Tracheophyta; Subdiv. [] Spermatophytina; Order: Lamiales; Family Lamiaceae; Subfam. Nepetoideae; Gender: Origanum; Binomial name; Origanum vulgare, L. 1753 [1]) and Primrose (Primula veris - Regn Plantae; Subregn Viridiplantae;

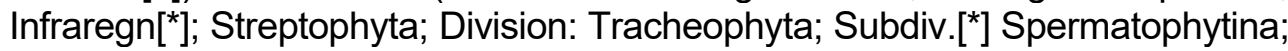
Order: Ericales; Family: Primulaceae; Gender: Primula; Binomial name; Primula veris, L. 1753 [1]) collected from Tomesti (lasi, Romania). The primary processing of the plants involved drying under the indirect influence of the sun, by placing them in a single layer in a well-ventilated space. Subsequently, the dried plants (stems, flowers and leaves) were crushed using a food mill and stored in a sealed, clean and dry laboratory flask until further use.

All necessary reagents or reference standards were of analytical quality (p.a.) (Chemical Company, Romania).

\section{Extraction methodology}

For the practical application of the extraction process it was used the same solvent as in our previous studies (in the case of maceration and heat extraction), respectively a solvent having the quality conditions required and accepted by both the food and agriculture industry [12, 13], meaning the ethanol. The concentration of ethanol (Chemical Company, Romania) was $96 \%$, established after the preliminary tests in case of maceration.

The proper weighing of the powder from each plant was done using an analytical balance, RADWAG AC type $(230 \mathrm{~V} / 400 \mathrm{~W}, 50 \mathrm{~Hz})$. The established amount of vegetal powder $(1 \mathrm{~g})$ was dispersed separately in adequate volume of ethanol, in order to respect the considered solid-liquid ratio (1/10, 1/15 and 1/20).

Ultrasound-assisted extraction (sonoextraction) was performed in an ultrasonic bath, SONOREX RK type $100 \mathrm{H}$ (produced by Bandeline Electronic $\mathrm{GmbH} \&$ Co.KG, Berlin, Germany, $35 \mathrm{kHz}, 320 \mathrm{~W}$ ). This set-up allowed the control of extraction time and temperature. The extraction process was carried out at two constant temperatures $\left(35^{\circ} \mathrm{C}\right.$ and $\left.45^{\circ} \mathrm{C}\right)$. At each temperature, there were considered two different extraction times (10 and $15 \mathrm{~min}$ ).

The extraction was practically performed in two manners: (i) with reagents in a static system for the entire period of time required for extraction; (ii) by stirring the phases for the entire period of time required extraction. After the established extraction time, the biphasic systems were separated and the filtrates were collected in a glass laboratory flask and used for the quantitative and qualitative characterization of plants extracts. 


\section{Determination of extraction yield}

In order to determine the extraction yield (eq.1) a sample of $5 \mathrm{~mL}$ of each extract was evaporated to dryness at constant temperature up to $60^{\circ} \mathrm{C}$ using a thermostatic oven.

$$
\eta \%=\frac{m_{\text {residue }} \cdot V_{\text {extract }}}{n_{\text {extract }} \cdot m_{\text {solid sample }}} \cdot 100
$$

where, $m_{\text {residue }}$ represents the mass of the residue obtained after evaporation to dryness, (g); $V_{\text {extract }}$ - the volume of the extract sample for evaporation to dryness, $(\mathrm{mL}) ; n_{\text {extract }}$ - the total volume of extract obtained after the liquidsolid extraction, $(\mathrm{mL}) ; m_{\text {solid sample }}$ - the mass of vegetal powder introduced in liquid-solid extraction process $(\mathrm{g})$.

\section{Physical-chemical characterization of the vegetal extract}

For physical-chemical characterization of the vegetal extract it was used the UV-Vis spectrophotometer-based method, with a UV-Vis spectrophotometer Jasco V-550 model in order to register the spectra in the 200-800 $\mathrm{nm}$ region of the prepared vegetal extracts.

\section{Quantitative characterization of the vegetal extract}

The quantitative characterization of the vegetal extracts consisted of two types of analysis:

(i) Total polyphenolic compounds (TPC) content - determined according to Folin-Ciocalteu procedure, using the gallic acid (GAE) as reference standard to register the calibration curve [14]. The absorbance was measurement at $765 \mathrm{~nm}$ and the results were expressed in $\mu \mathrm{g}$ GAE/g;

(ii) Total flavonoids (TF) content - determined according to spectrophotometerbased method using a solution of $\mathrm{AlCl}_{3} 2 \%$ in the presence of methanol [14]. The results were expressed in $\mu \mathrm{g} Q \mathrm{QE} / \mathrm{g}$, considering the quercitin (QE)-based reference calibration curve.

\section{Assessment of bio-insecticidal activity of the prepared vegetal extracts}

It was worked with the Origanum vulgare and Artemisia absinthium extracts prepared by sono-extraction at $45^{\circ} \mathrm{C}$. As a pest it was tested on ladybug bean (Acanthoscelides obsoletus) which causes bean disease during storage. A number of 20 adults of the ladybug bean species were placed in a 8-liter working enclosure. For pest control, the working protocol includes: 
(i) the vegetal extract application using two techniques: directly, consisting in spraying of vegetal extract (in raw form and $100 \%$ concentration) on the bean seeds, and indirectly, consisting in spraying vegetal extract on a porous cellulose support to ensure the creation of a saturated atmosphere with extraction compounds in the working enclosure;

(ii) the pest monitoring carried out at well-established intervals $(2,8$, $12,24,48,72,96,120,144,168 \mathrm{~h}$ ) after the treatment application. The monitoring consisted in the identification of the number of eggs laid, as well as the establishment of the effectiveness of the treatment applied by studying the neuroleptic manifestations of pests (hyperactivity, inconsistency of the hind limbs, unnatural behaviours, etc.) and the identifying of the mortality rate of adults. The method used for monitoring was adapted after Asawalam et al. (2006) [15]. The mortality rate of insects was calculated using eq.(2) [15].

$$
\% \text { mortality }=\frac{N_{d}}{N_{n}} \cdot 100
$$

where $N_{d}$ represents the number of dead insects and $N_{0}$ is the number of initial tested insects.

\section{REFERENCES}

1. A. Dekebo; Plant Extracts, in Plant Extracts; A. Dekebo Ed.; Intech, 2019, Introductory Chapter, pp.1-10.

2. A. Barbulova, G. Colucci, F. Apone; Cosmetics, 2015, 2, 82-92.

3. A.S. Ribeiro, M. Estanqueiro, M.B. Oliveira, J.M.S. Lobo; Cosmetics, 2015, 2, 48-65.

4. D. Suteu, L. Rusu, C. Zaharia, M. Badeanu, G.M. Daraban; Appl. Sci., 2020, 10, 8913, 21pg.

5. H. Antolak, D.Kregiel; Food Preservatives from Plants, in Food Additives, D.N. Karunaratne, G. Pamunuwa, Eds., Intech, Chapter 3, 2017, 45-85.

6. H.O. Saxena, Y.C. Tripathi, G. Pawar, A. Kakkar, N. Mohammad; Botanicals as Biopesticides: Active chemical constituents and biocidal action, in Familiarizing with local biodiversity: Notes on Systematics Of Plants And Insects, P.K. Khatri, P.M. Meshram, (Eds.), Tropical Forest Research Institute (Indian Council of Forestry and Education), PO, RFRC, Mandla Rood Jabalpur-482021, 2014, Chapter 21, 219-240.

7. S.K. Okwute; Plants as Potential Sources of Pesticidal Agents: A Review, in Pesticides - Advances, in Chemical and Botanical Pesticides, Soundararajan, R.P. (Ed.), InTech, 2012, Chapter 9, 207- 232. 
8. G.M.W. Lengai, J.W. Muthomi, E.R. Mbega; Scientific African, 7, 2020, e00239.

9. Y. Tembo, A.G. Mkindi, P.A. Mkenda, N. Mpumi, R. Mwanauta, P.C. Stevenson, P. A. Ndakidemi, S.R. Belmain; Frontiers in Plant Science, 2018, 9, Article 1425, 10pg.

10. B. Singh, A. Kaur; LWT - Food Sci Technol, 2018, 87, 93-101.

11. J.J. Villaverde, P. Sandin-Espana, B. Sevilla-Moran, C. Lopez-Goti, J.L. AlonsoPrados; BioResource, 2016, 11(2), 5618-5640.

12. P.O. Lamuka; Encyclopedia of Food Safety, 2014, 4, 20-26.

13. S. Quijas, P. Balvanera; Biodiversity and Ecosystem Services, in Encyclopedia of Biodiversity (Second Edition), Levin S.A. (Ed.), Elsevier Inc. All, 2013, 341-356.

14. L. Pavun, S. Uskokovic-Markovic, M. Jelikic-Stankov, D. Đikanovic, P. Đurdevic; Czech J. Food Sci., 2018, 36(3), 233-238.

15. E.F. Asawalam, S.O. Emosairue, A. Hassanali; Electron. J. Environ. Agric. Food Chem., 2006, 5, 1195-1204.

16. R.E. Ghitescu, I. Volf, C. Carausu, A.M. Bühlmann, I.A. Gilca, V.I. Popa; Ultrasonics Sonochemistry, 2015, 22, 535-541.

17. S. Boonkird, C. Phisalaphong, M. Phisalaphong; Ultrason. Sonochem., 2008, 15, 1075-1079.

18. G. Daraban, M. Badeanu, L. Rusu, D. Suteu; Scientific Papers series of Horticulture (USAMV lasi, Romania), 2018, 61 (1), 269-274.

19. G. Daraban, M. Badeanu, L. Rusu, D. Suteu; Bull IPI (Iasi, Romania), 2018, 64 (68), 33-41. 